\title{
BENTUK TARI TROEN U LAOT PADA MASYARAKAT PIDIE KABUPATEN ACEH PIDIE
}

\author{
IKE WILDA YUSNI \\ Prodi PendidikanTari
}

\begin{abstract}
Penelitian ini merupakan kajian mengenai. Bentuk Tari Troen U Laot pada masyarakat Pidie Kabupaten Aceh Pidie. Tujuan penelitian adalah untuk mendiskripsikan Bentuk Tari Troen U Laot pada masyarakat Pidie Kabupaten Aceh Pidie.

Teori yang digunakan dalam penelitian ini adalah teori Bentuk dari Murgianto yang memuat tentang gerak, Teori ini menjadi acuan untuk untuk mengupas permasalahan yang ada dalam tari Troen U Laot.

Waktu yang digunakan dalam penelitian untuk membahas Troen U Laot dilakukan sejak Januari 2016 sampai Maret 2016.Tempat penelitian dilakukan di Kecamatan Simpang Tiga Kabupaten Pidie.Populasi pada penelitian ini sekaligus menjadi sampel penelitian yaitu tokoh adat, seniman, dan penari adat. Teknik Pengumpulan data meliputi studi ke pustakaan,wawancara, observasi dan dokumentasi.

Berdasarkan hasil penelitian bahwa sebagian besar mata pencaharian masyarakat Pidie adalah nelayan.Dari kegiatan nelayan tersebut maka diciptakan Tari Troen U Laot.Dalam Troen ULaot terkandung bentuk gerak batiniah tari ini mencerminkan kehidupan para nelayan yang membutuhkan perlengkapan jala untuk menjalankan aktivitasnya. Sedang bentuk lahiriah diwujudkan lewat ragam-ragam gerak yang tersusun, meliputi ragam gerak :Ayoen jaroe,poh jaroe ukeh, poh jaroe unen, poh jaroe uwie, syukor, poh jaroe yub, peuget jarring, teumirong bak jaring.
\end{abstract}

Kata kunci : Bentuk Tari Troen U Laot Pada Masyarakat Pidie Kabupaten Aceh Pidie. 


\section{PENDAHULUAN}

Provinsi Aceh merupakan salah satu satu Provinsi yang ada di Indonesia yang terletak di ujung ( timur, barat, utara, selatan,) Pulau Sumatra yang memiliki ibu kota Banda Aceh, Provinsi Aceh terbagi menjadi 1a8 wilayah Kabupaten dan 5 ( lima ) wilayah kotamadya. Pidie merupakan salah satu Kabupaten di Provinsi Aceh, yang secara formal dibentuk melalaui undang-undang nomor 7 tahun 1956 nomor 58 . Namun bukan berarti bahwa identitas Pidie baru muncul tahun 1956 sebagai suatru daerah, karena Pidie sudah eksis dan menjadi suatu negeri yang sangat penting di Sumatera bagian utara jauh sebelum kerajaan Aceh Darussalam muncul. Pidie menjadi salah satu Pelabuhan penting pedagang asin. Dengan wilayah yang terbagi atas daerah persawahan, laut serta hutan-hutan kecil, sehingga di Kabupaten Pidie dikenal subur akan hasil pertanian sawahnya, perkebunannya dan hasil lautnya yang melimpah. Pada tahun 2007 Kabupaten Pidie mengalami pemekaran menjadi dua Kabupaten yaitu Pidie sebagai Kabupaten Induk dan Pidie Jaya sebagai Kabupaten pemekaran. Kabupaten terdiri dari 30 Kecamatan misalnya seperti Singkil, Delima, Padang Tiji, Mutiara Tiga, Batee, Simpang Tiga, Kembang Tanjung, Peukon Baro, Indra Jaya, Grong-Grong, Mutiara Timur, Tiro Mila, Sakti, Titue, Kemala, Tangse, Geumpa, Mane dan sebagainya.

Kabupaten Pidie yang terbentang diantara $04, \quad 30-4,60$ lintang utara dan 95,75-96,20 bujur Timur merupakan salah satu Kabupaten dalam wilayah Provinsi Aceh. Luas wilayah Kabupaten Pidie mencapai 3.086,90 km. wilayah Kabupaten Pidie sebelah Timur berbatasan dengan Kabupaten Pidie jaya, sebelah Barat berbatasan dengan Kabupaten Aceh Besar, sebelah Utara bebatasan dengan Selat Malaka dan sebelah Selatan berbatasan dengan Kabupaten Aceh Barat. Aceh merupakan kwasan yang sangat kaya dengan seni budayanya.Seni budaya yang khas yang dimilki Aceh seperti tari troen $u$ laot, troen u blang, musare-musaree, likok pulo, laweut, poh, dan lain-lain. Suku Aceh yang berda di Aceh Pidie Provinsi Nanggroe Aceh Darussalam 
( NAD ) memiliki kesenian sebagaimana dimilki suku-suku bangsa lainnya di Indonesia. Tarian troen $u$ laot adalah salah satu tarian yang berasal dari Kabupaten Pidie.Tarian ini menjadi bagian yang tak dapat dipisahkan dalam kehidupan masyarakat Aceh terutama masyarakat Pidie, artinya tarian ini telah mengalami perkembangan pesat karena tarian ini telah menyebar di kota-kota lainnya seperti di Kotamadya Banda Aceh.

Penelitian menuliskan sebuah tarian yang ada di Aceh yang harus di sebagai warisan budaya tarian ini di kenal nama Troen U Laot tarian ini diciptakan oleh ibu Yusrizal Pada tahun 1980-an tempat tinggal di Pidie, tarian ini menceritakan bagaimana kehidupan masyarakat Aceh Pidie yang bertempat tinggal di pesisir pantai, dimana sebagian masyarakat Aceh Pidie bermata pencaharian sebagai nelayan. Tari Troen U Laot adalah salah satu tarian yang tradisional yang berasal dari daerah Pidie tarian ini biasanya dibawakan sekelompok penari lakilaki dan penari perempuan yang menari menggunakan tali sebagai atribut menarinya.Tarian Troen U Laot merupakan tarian yang menggambarkan tentang aktivitas para nelayan Aceh Pidie saat menangkap ikan di laut.Tarian ini sering ditampilkan di berbagai acara seperti upacara penyambutan, acara adat, dan acra budaya. Menurut sejarah tari troen $\mathrm{u}$ laot terinspirasi dari tradisi menarik jala yang sering dilakukan pada masyarakat Aceh Pidie kegitan menarik jala sudah dilakukan pada masyarakt pesisir pantai Aceh sejak lam. Saat menangkap ikan, mereka melepas dan menarik jala secara bergotong royong. Setelah selesai menangkap ikan hasil yang mereka dapatkan akan dibagi-bagi pada warga saat menarik jala. Tradisi tersebut direfleksikan dalam sebuah tarian yang di sebut tari troen $u$ laot.

Hasil wawancara dengan ibu Yusrizal pada tanggal 24 November 2013 Pemerintah Banda Aceh bekerja sama dengan pariwisata Banda Aceh mengelar tari Troen U Loat yang diikuti oleh seluruh para yang berada di Banda Aceh. Selain kegiatan ini tersebut diikuti dengan pameran baenda-benda yang 
bersejarah di Banda Aceh yang secara resmi menyatakan bahwa tari Troen U Laot merupakan tarian yang trdisi dan sekarang sudah menjadi sebuah tarian kreasi dan tidak ada pergantian gerak di masyarakat Aceh. Tari Troen U Loat merupakan tarian yang berasal dari aceh Pidie untuk menjaga identits tarian Troen U Loat di daerah lain tempat masyarakat pendukungnya menetap dan berkembang. Menjaga identitas melalui tarian tardisi dan memelihara adat istiadat tarian tersebut dan tarian ini telah menjadi kreasi . tarian Troen U Laot merupakan tarian yang turun temurun yang dilakukan oleh masyarakat Aceh Pidie disetiap turun ke laut untuk menjala iakn yang di selingi dengan acara peusejuik atau tepung tawar dan kenduri tari Troen U Laot merupakan tarian yang sering dilkukan oleh masyarakat Pidie di setiap turun ke laut mencari kehidupan dengan peralatan yang sederhana troen $\mathrm{u}$ laot lebih merakyat dan berkembang di sanggar-sanggar daerah Aceh Troen $\mathrm{U}$ Loat adalah tarian yang berkembang pada kebudayaan suku Aceh Pidie, salah satu etnik yang terdapat pada wilayah daerah Kabupaten Aceh Pidie. Melihat tari ini berkembang dari tujuannya, penulis tertarik untuk meneliti tarian ini dengan judul " Bentuk Tari Troen U Laot Pada Masyarakat Pidie Kabupaten Aceh Pidie".

\section{Landasan Teori}

Untuk membahas bentuk Tari Troen U Laot Pada Masyarakat Pidie Kabupaten Aceh Pidie menggunakan Teori Murgianto

\section{Lokasi dan Waktu Penelitian}

Tempat Penelitian ini adalah Kecamatan Simpang Tiga Kabupaten Pidie

\section{TeknikAnalisis Data}

Penulis melakukan observasi secara langsung karena bertujuan untuk mengetahui bagaimana gabungan bentuk tari Troen U laot pada masyarakt Pidie Kabupaten Aceh Pidie. 


\section{PopulasidanSampel}

\section{Populasi}

Populasi dalam penelitian ini adalah beberapa tokoh-tokoh adat masyarakat dan seniman-seniman yang mengerti tentang tari Troen $U$ Laot.

\section{Sampel}

Sampel dalam penelitian ini adalah dua orang tokoh adat dan satu orang seniman / masyarakat sekaligus penari yang mengetahui tentang tari troen u laot

\section{Teknik Pengumpulan Data}

Teknik pengumpulan data adalah sebagai berikut:

1. Studikepustakaan

2. Observasi

3. Wawancara

4. Dokumentasi mencapai 3.086,90 km. Wilayah Kabupaten Sebelah Timur berbatasan dengan Kabupaten Pidie Jaya, Barat berbatasan dengan Kabupaten Aceh Besar, sebelah Utara berbatasan dengan Selat Malaka dan sebelah Selatan berbatasan dengan Kabupaten Aceh Barat.

Aceh merupakan kawasan yang sangat kaya dengan seni budayanya.Aceh mempunyai aneka seni budaya yang khas seperti taritarian dan budaya lainnya seperti: Meuseukee Eungkot ( sebuah tradisi di wilayah Aceh Barat ) dan peusijiuek ( tepung tawar ). Provinsi Aceh memiliki kekayaan tari-tarian yang sangat banyak dan juga sangat mengagumkan. Beberapa tarian yang terkenal di tingkat nasional dan bahkan dunia merupakan tarian yang berasal dari Aceh yaitu : tari rateb, meuseukat, seudati dan tari saman.

\section{ISI}

Kabupaten Pidie yang membentang di antara 04,30-4,60 Lintang Utara dan 95,75-96,20 Bujur4 Timur merupakan salah satu Kabupaten dalamn wilayah Provinsi Aceh Luas Wilayah Kabupaten Pidie
Sejarah Tari Troen U Laot Pada Masyarakat Pidie

Troen U Laot merupakan hasil dari satu jenis tarian yaitu : tari tarek pukat dua tarian tersebut bisa di pentaskan secara terpisah karena sebenarnya dua tarian itu berdiri 
sendiri-sendiri. Penggabungan kedua tarian ini berdasrkan kesamaan makna yaitu semangat dan samasama menceritakan tentang mata pencaharian masyarakat Aceh. Penari dalam tarian ini 8 penari 4 penari perempuan dan 4 penari lakilaki.Troen U Laot menggambarkan aktivitas para nelayan yang menangkap ikan di laut.

Tari troen $u$ laot ini merupakan tarian yang berasal dari Aceh Pidie, yang diciptakan oleh ibu yusrizal pada tahun 1980. Awalnya tarian ii diciptakan dalam rangka meriahkan Kongres Pemuda tahun 1980 di Banda Aceh. Para penari pertama tari troen $\mathrm{u}$ laot tersebut sudah berpencar satu persatu, ada yang sudah menikah dan tinggal di Banda Aceh, dengan adanya pembubaran satu persatu penari tersebut dari suatu tempat ke tempat lainnya. Terjadilah perkembangan diberbagai daerah Aceh seperti tepatnya di Kota Banda Aceh sekarang menjadi sanggar tersebut yang bernama bapak syem ( penari pertama troen u laot ).
Gambar Ragam Troen u Laot

a. Intro Masuk

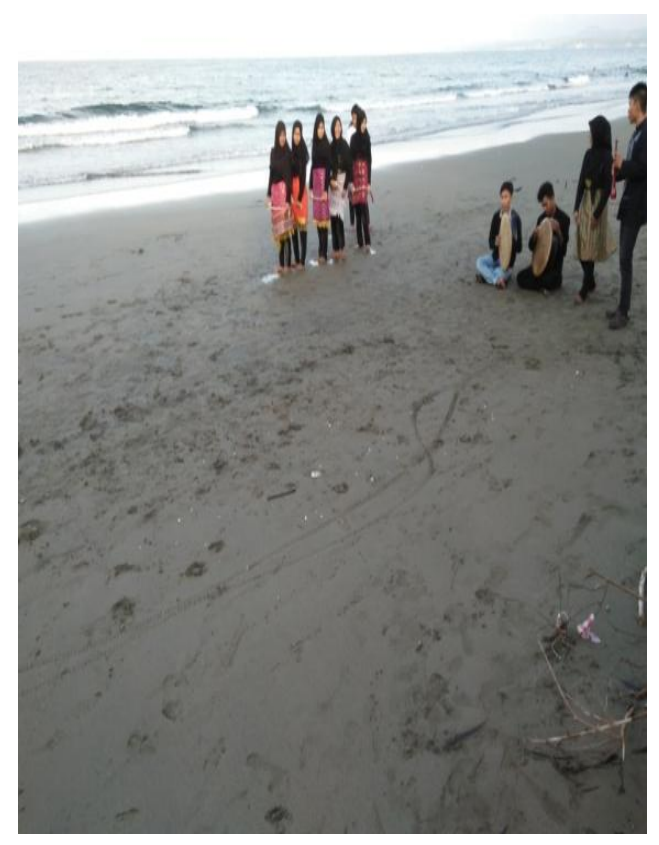

b. Poh Jaroe Ukeh

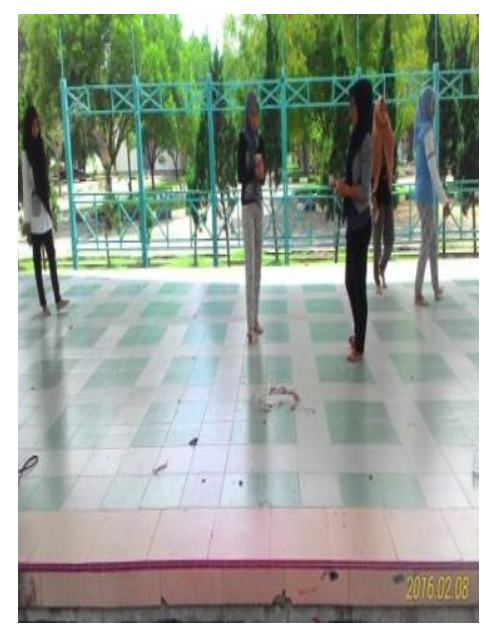


c. Poh Jaroe uwie

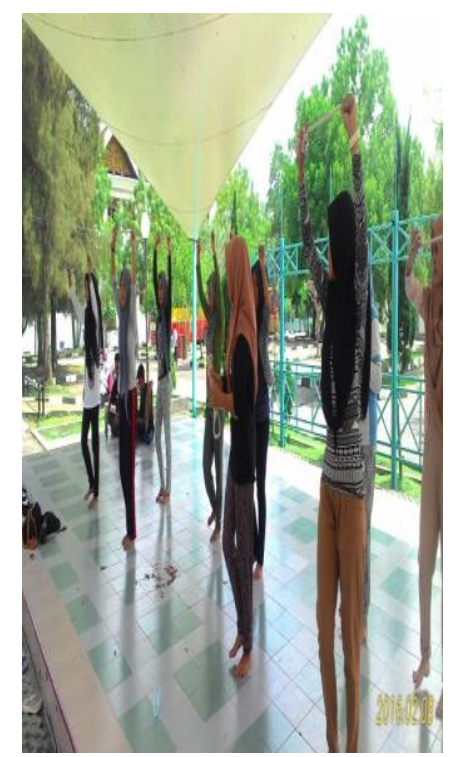

d. Ayoen Jaroe

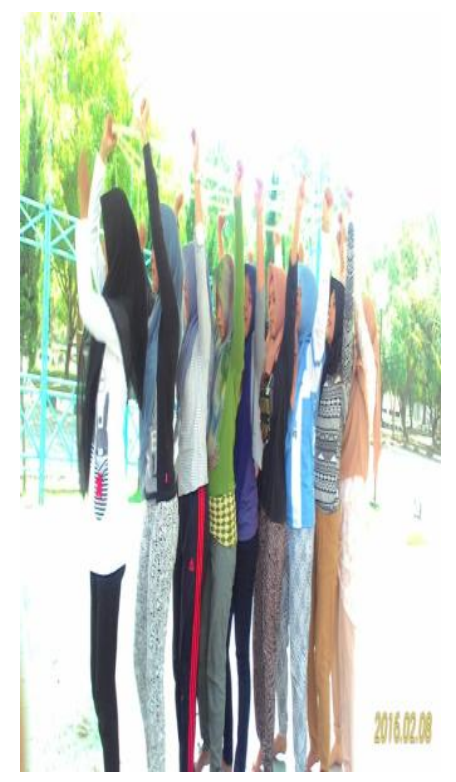

e. Peuget jarring

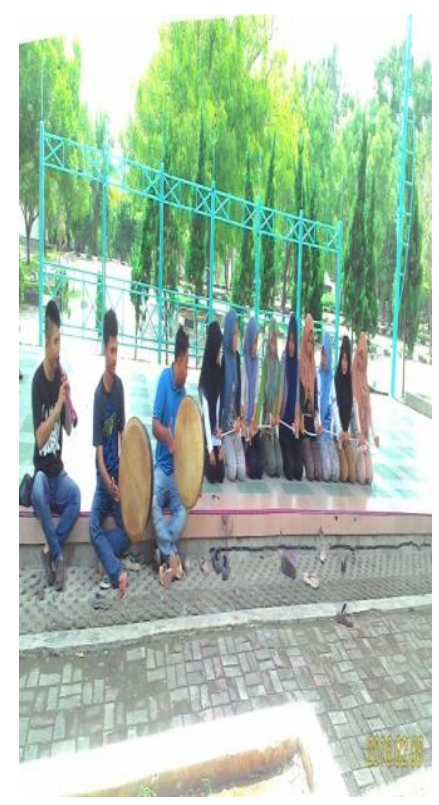




\section{PENUTUP}

\section{Kesimpulan}

Dari semua yang sudahpat memperoleh di teliti di lapangan dan berdasarkan uraian yang sudah dijelaskan mulai dari latar belakang sampai pembahasaan, maka penulis dapat memperoleh beberapa kesimpulan tentang tari Troen U laot

1. TarianTroen $u$ Laot artinya bernelayan. Tarian ini diciptakan oleh ibu yusrizal pada tahun 1980. Awalnya tarian ini kongres I tahun 1980 di Banda Aceh. Tari troen ini salah satu tarian yang masih berkembang hingga sekarang di Aceh tepatnya di Kabupaten Pidie. Tarian ini menceritakan tentang kegiatan masyarakat Aceh pada saat bekerja sebagai nelayan dan bertani.
2. Sebagai salah satu tarian yang masih berkembang pada masyarakat Kabupaten Pidie, tari troen $u$ laot memiliki fungsi hiburan dan fungsi social dalam masyarakat.

3. Tari troen $u$ laot kini mulai di lestarikan dan di pertunjukkan di berbagai acra seperti : hut Aceh, Hut Kemerdekaan, Republik Indonesia, Hut Kabupaten Aceh Pidie dan acara lainnya.

\section{Saran}

Dari hasil kesimpulan penelitian diatas, maka dapat diajikan beberpa saran antara lain sebagai berikut :

1. Pemerintah kabupaten Pidie melalui Dinas Kebudayaan dan Pariwisata hendaknya lebih memperhatikan keberadaan tari troen u laot yang merupakan 
2. salah satu kesenian budaya daerah. Upaya tersebut dapat dilakukan dengan seringnya menampilkan tari troen $u$ laot pada acara-acara yang berkaitan dengan tradisional yang ada di Provinsi Aceh Kabupaten Aceh Pidie .

3. Agar masyarakat khususnya di kabupaten Aceh Pidie, mengenal tari troen $u$ laot, tetap menjaga dan melestarikan nilai-nilai yang terkandung dalam kesenian tersebut.

4. Seniman pada umumnya agar lebih mengembangkan kesenian tarian terutama tari troen $u$ laot supaya lebih menarik generasi muda untuk mempelajari tari tersebut sebagai salah satu kekayaan budaya di Kabupaten Pidie.

\section{DAFTAR PUSTAKA}

\author{
Suharsimi, 2006.Prosedur \\ Penelitian. Jakarta : Rineka Cipta \\ Burhan Firdaus, ed. \\ 1986.Ensikopedi Musik dan \\ Tari Daerah,Profinsi Daerah \\ Istimewa Aceh.Banda \\ Aceh:Pusat Penelitian \\ Sejarah dan Budaya, Proyek \\ Inventasi dan Dokumentasi \\ Kebudayaan Daerah.
}

Daryanto,1998.Kamus Lengkap

Baahasa Indonesia.Surabaya:Apollo

Departemen Pendidikan dan Kebudayaan.( 1981 ).

Kesenian Tradisional Aceh

Banda Aceh.

Djalal Muchtar dan Athaillah.( 1980

). Kesenian Tradisional

Aceh.

Hadi, Sumandiyo, 2005. Sosiologi Tari. Yogyakarta: Penerbit Pustaka.

Hadi Y. Sumandiyo, 1983.

Pengantar Krativitas Tari. Yogyakarta: Akademi Seni Tari Indonesia.

Haryanti Huthoari, 2012. "Fungsi dan Makna Gerak Tari Rampoe Aceh Pada Masyarakat Kota Langsa ( Nanggroe Aceh Darussalam )". Skripsi untuk memperoleh gelar S1 pada Program studi 
seni tari : Universitas Negeri

Medan.

Hasymy.A. ( 1983 ). Kebudayaan

Dalam Sejarah. Penerbit BEUNA : Jakarta.

Kamisa. 1997. Kamus Lengkap

Bahasa Indonesia.Penerbit : Kartika

Surabaya.

Koentjraningrat, 2004. Kebudayaan

Mentalitas dan Pembangunan,

Jakarta :

Gramedia Pustaka Utama.

Langer Suzanne. K, 1988, Problems

Of Art, Terjemahan

F.X.Widyamanto,

Bandung : Akademi Seni Tari Indonesia.

Murgianto, Sal, 1983, Koroegrafi

Pengetahuan Dasar

Komposisi Tari, Jakarta:

(Direktorat Jenderal)

Pendidikan Dasar dan

Menengah Departemen

Pendidikan dan Kebudayaan.

Padmo Pramana. Tata Teknik

Pentas. Jakarta: Departemen

Pendidikan dan Kebudayaan.

Id.wikipedia.org/wiki/Aceh Sejarah. 